\title{
Alcances e limites da crítica no contexto da cultura política do consumo
}

\author{
ISLEIDE A. FONTENELLE ${ }^{I}$
}

\section{Introdução: coisas fora de ordem}

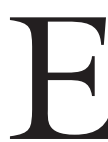

M JUNHO de 2013, as cidades brasileiras foram ocupadas por manifestações crescentes e heterogêneas, cuja evolução se deu em dois momentos: num primeiro, comandado pelo Movimento Passe Livre (MPL), ${ }^{1} \mathrm{com}$ uma agenda clara e focada, reivindicando a revogação do aumento da tarifa de ônibus; e, num segundo, quando se deu a adesão em massa à forma de protesto iniciada pelo MPL, quando milhares foram às ruas com uma pauta ampla de reclamações e reivindicações.

Para Sakamoto (2013, p.97), esse segundo momento teria se iniciado na primeira grande manifestação em massa do dia 17/6, quando foi marcado um protesto de apoio às reivindicações do MPL e de repúdio à violência policial que tinha ocorrido na manifestação do dia 13/6. No dia 17, surge uma massa heterogênea e descontente, pois "o chamado via redes sociais trouxe as próprias redes sociais para a rua" (ibidem). O autor constata que, nas manifestações de rua, grande parte dos cartazes apresentava comentários anteriormente postados no Facebook e no Twitter.

Nesse momento, slogans de duas campanhas publicitárias começam a aparecer e a se tornar, de certa forma, as marcas registradas do movimento: o "vem pra rua", um slogan da campanha da marca de automóveis italiana Fiat; e "o gigante não está mais adormecido", slogan da marca de uísque escocês Johnnie Walker, que acabou sendo adaptado para "o gigante acordou".

"Vem pra rua" acabou se tornando o chamado "oficial" dos manifestantes nas redes sociais, assim como o grito de guerra durante os protestos de rua. Insurgindo-se, em especial, contra a maneira violenta como a polícia reagiu às primeiras manifestações, a população foi para a rua, assumindo que a rua era um espaço público e que, portanto, era o público quem deveria definir a agenda sobre o que celebrar ou reivindicar nesse espaço. Foi postado um vídeo no Youtube que focou, especialmente, na relação entre manifestantes e polícia, sob o fundo musical do "vem pra rua". ${ }^{2}$

"O gigante acordou" passou a ser uma menção direta à campanha da marca de uísque. Subvertendo o sentido do anúncio, que apontava como o Brasil 
havia finalmente despertado como potência econômica, os manifestantes indicavam que os brasileiros haviam acordado para a luta, a fim de questionar aquela imagem fácil de progresso econômico e apontar o que não era possível celebrar.

Segundo reportagem da revista Exame, com base no levantamento da agência de mídia digital Today, no dia da grande manifestação de $17 / 6$, foram registradas " 548.944 publicações, entre posts e comentários nas principais redes sociais. O Twitter foi a rede social mais utilizada para citar as manifestações, registrando 483.839 (88\%) das publicações. Entre as hashtags mais utilizadas estão "\#vemprarua, \#ogiganteacordou, \#protestosp, \#mudabrasil e \#semviolencia” (Campri, 2013 - grifos meus) .

Foi também postado um vídeo no Facebook que, até a data de 18.6.2013 - um dia após a primeira grande manifestação em massa - teve 74 mil visualizações. $\mathrm{O}$ vídeo funde cenas reais das manifestações às imagens do comercial da Johnnie Walker com o pano de fundo musical do "vem pra rua". ${ }^{3}$

A primeira interpretação que o uso dos slogans poderia remeter era a de que essas marcas seriam alvo dos protestos, como já havia ocorrido nos que ficaram conhecidos como os movimentos antiglobalização, que eclodiram no início deste século, quando grandes marcas publicitárias foram alvo de ataques. Tratava-se de um momento na cultura do consumo no qual as marcas globais estavam se tornando muito poderosas, sob a lógica do funcionamento do capitalismo imaterial e global (Gorz, 2005; Fontenelle, 2002). Atingir sua reputação passou a ser uma estratégia política, expondo os "bastidores das marcas", alvejando-as institucionalmente e forçando as corporações a práticas mais responsáveis, como melhores salários e condições de trabalho (Klein, 2002).

Nessa mesma linha, uma segunda interpretação poderia ser a de que o uso dos slogans representava uma forma de ação da "culture jamming": uma subversão do sentido da marca, uma sátira, "a apropriação de uma identidade de marca ou anúncio comercial com um objetivo subversivo, frequentemente, político" (Carducci, 2006, p.117). "Culture jamming" foi um termo cunhado pela banda de audiocolagem Negativland, em 1984, propondo uma reescrita da publicidade original, que alteraria o seu sentido e criaria um novo significado que o movimento considera ser representativo daquilo que a publicidade deveria passar.

Sem dúvida, as manifestações no Brasil subverteram o sentido original das campanhas publicitárias. E não deixa de ser uma ironia os protestos se apropriarem de uma marca de automóveis para fazer uma chamada às ruas, justamente contrapondo o cidadão ao consumidor de carros. ${ }^{4}$ Do mesmo modo, quando as manifestações usaram o slogan da campanha Johnnie Walker, é possível perceber a ironia contida na subversão do comercial: a sátira a uma farsa da ideia do "crescimento brasileiro".

Mas o que se viu não foi um movimento contra os carros, contra as marcas ou contra as corporações. Não se estava questionando se e até que ponto 
o mercado poderia ser responsabilizado pela privatização do espaço público ou pela mercantilização de serviços públicos como transporte, educação, saúde. A motivação principal também não foi questionar a publicidade como força dominante de nossa época, proposição presente na criação da revista canadense Adbusters, representante por excelência da culture jamming (Heath; Potter, 2005; Carducci, 2006) e grande foco dos movimentos de resistência da década de 1990. As marcas e seus slogans serviram apenas de inspiração, com o sentido invertido, por aquilo que veicularam em seus anúncios. E esse uso aponta para a possibilidade de um imaginário cultural já formatado pela lógica do consumo.

A hipótese que se levanta é a de que esses slogans foram tomados como aliados no processo de construção do movimento de crítica a um estado de coisas que, em certa ordem temporal, seria: a reivindicação do direito de protestar e de assumir o espaço público; a crítica à truculência da polícia, à falta de atendimento aos serviços públicos e à corrupção estatal. Assim, o grande alvo foi o governo, desde a reivindicação inicial, de revogação do aumento da tarifa de ônibus, até as manifestações em massa, nas quais se sobressaiu uma pauta estendida de protestos e reivindicações.

Tal perfil de críticas e reivindicações também compõe grande parte das interpretações acadêmicas sobre as manifestações de junho, mesmo se observadas de diferentes espectros ideológicos (Gohn, 2014; Figueiredo et al., 2014; Maricato et al., 2013; Caldeira, 2014). Destacam-se: a questão urbana e a afirmação do direito à cidade; a má qualidade dos serviços públicos; e a desilusão com a democracia representativa. Assim, o objeto maior de crítica, segundo essas interpretações, continua sendo o governo; embora as opiniões se dividam entre uma crítica mais ampla ao Estado neoliberal e às ações concretas dos governos, em especial o federal, que não havia realizado suas promessas, seja porque não foi capaz de desenvolver um serviço público que atendesse à expansão dos grandes centros urbanos; seja porque se perdeu em meio à corrupção da máquina estatal; seja até mesmo porque realizou certos direitos sociais, mas não os ampliou. Há, porém, quase uma unanimidade, entre esses autores, quando o que se coloca em causa é a ação da polícia e à forma como o governo - municipal, estadual e federal - reagiu aos protestos. De maneira geral, o governo é acusado pela ação repressiva e brutal da polícia e de agir de forma errática, sem dar a devida importância aos protestos inicialmente; e, depois, já não sabia como responder ao amplo espectro de reivindicações, oscilando entre a promessa de um pacto de melhoria dos serviços públicos a uma ampla reforma política.

A crítica ao governo, portanto, está na causa e na consequência dos fatos; assim como, na interpretação dos fatos. E isso joga água no moinho da cultura política do consumo. Não por acaso, se as campanhas das marcas Fiat e Johnnie Walker foram apropriadas para oferecer um sentido político invertido às manifestações, a marca Coca-Cola colocou, literalmente, as manifestações no interior de um dos seus comerciais. Um mês após os protestos de junho, a marca 
veiculou um anúncio publicitário adaptado de sua campanha "câmeras da felicidade", que tinha o objetivo mais amplo de mostrar cenas "positivas" captadas por câmeras de segurança, dispositivo eletrônico que costuma estar associado a fatos negativos. No anúncio, as câmeras da felicidade captam imagens das manifestações e, sobre elas, aparece a palavra "esperança”. Nesse sentido, a marca explicitou qual poderia ser o real sentido da política na lógica do mercado: indicando que a esperança estaria na medida em que pudesse existir um mundo no qual mercadorias e protestos conviveriam pacificamente.

A Coca-Cola tem sido uma marca associada a campanhas publicitárias focadas no papel das empresas e dos consumidores em "fazer o bem". Especialistas em comunicação publicitária já apontaram como a Coca-Cola, entre outras marcas, vem investindo na mensagem de que é possível "mudar o mundo" a partir do empenho das grandes corporações (Scholz, 2013). Isso significa que grandes marcas já vinham veiculando um forte conteúdo social e uma interpretação do lugar do político, antes mesmo dos protestos de junho. A maneira como o comercial ressignificou as manifestações apenas ilustra mais uma camada desse processo e de como ele pode engolfar movimentos de resistência.

Análises acadêmicas que enfatizam os limites e alcances da crítica e da assimilação da crítica no interior da cultura do consumo costumam apontar para duas perspectivas: a primeira, que assume a impossibilidade da crítica radicalmente transformadora, a partir de reivindicações dos movimentos de consumidores e de suas "políticas de consumo"; e a segunda, que aponta para a apropriação da crítica pela cultura do consumo, mesmo quando tais manifestações não surgem a partir de demandas diretamente veiculadas ao mundo do consumo. Essas análises podem ser encontradas, dentre outras, na literatura acadêmica sobre os impasses da crítica no contexto da cultura de consumo (Heath; Potter, 2005; Frank, 1997); nas contradições do movimento antimarcas (Holt, 2002; Fontenelle 2010); e no surgimento do discurso corporativo sobre o consumidor responsável (Caruana; Crane, 2008; Fontenelle, 2013).

Os protestos de junho embaralharam essas duas perspectivas e deixaram as coisas literalmente fora de ordem, pois, por um lado, não se pode dizer que eram movimentos de consumidores contra empresas ou marcas, embora símbolos da cultura do consumo tenham sido subvertidos; por outro lado, os protestos tiveram seu ponto de origem em um tipo de reivindicação de cidadania (o uso do transporte público), que foi rapidamente assimilado pela cultura do consumo. A partir daí, a forma do movimento passa a ser moldada por certo imaginário do consumo, através da adesão das massas espetacularizadas, e da apropriação pela narrativa midiática e publicitária (Frederico, 2013). O objetivo principal deste artigo, portanto, é tomar os protestos brasileiros de 2013 como ilustração dos limites e alcances da crítica no contexto da cultura do consumo, tendo como pano de fundo a análise de seu novo estágio, que denomino de "cultura política do consumo". 
Para dar conta desse objetivo, o artigo está estruturado da seguinte forma: em primeiro lugar, aborda o contexto político e econômico mais amplo no qual a cultura política do consumo emerge. Entendo por cultura do consumo uma cultura impregnada da forma-mercadoria, assim como um modo de vida que foi se colando ao uso dos objetos e, com isso, ressignificando os valores, desejos e ilusões de uma época. Passada a primeira fase da cultura do consumo, que investiu na própria produção do consumidor (Bernays, 1928, p.63); assim como na fase seguinte, que investiu na moldagem cultural via imagens e marcas, a partir da imbricação da economia com a cultura (Jameson, 1991); o momento atual se configura como uma cultura política do consumo sob a égide do processo de privatização do público, em especial a partir do projeto neoliberal que passou a vigorar nas últimas décadas do século XX.

A segunda parte foca nos movimentos de crítica às grandes corporações e suas marcas, que surgiram no final do século XX, a fim de apontar para as (im)possibilidades da crítica nesse contexto e indicar como isso, até mesmo, serviu de inspiração para a constituição de uma nova etapa da cultura do consumo baseada na lógica da "empresa-cidadã" e de seu complemento necessário, o "consumidor-cidadão". Ver-se-á como é nesse contexto que se consolida uma nova concepção de política que torna as corporações sua estrela maior e que põe em xeque o modelo de governo. Cidadãos responsáveis pela coisa pública, empresas e consumidores tornam-se, assim, os principais agentes de um novo momento de "governança" 5 do mundo.

$\mathrm{Na}$ terceira parte, abordo as transformações econômicas e sociais que moldaram o consumidor-cidadão e que constituem a outra face da cultura política do consumo; enfatizando, ainda, o tipo de demanda que o consumidor-cidadão pode endereçar em manifestações de protestos, como as contemporâneas.

Em seguida, volto ao contexto brasileiro, a fim de buscar elucidar algumas especificidades dos protestos em um país periférico nessa nova política do mundo e em meio, também, a uma nova configuração do conflito social, onde aparecerem novos fenômenos da cultura política do consumo, como os rolezinhos e a produção musical de periferia denominada de "funk ostentação".

Por fim, ainda no contexto brasileiro, e tendo como pano de fundo o que foi discutido ao longo do artigo, volto às jornadas de junho com ênfase na insatisfação demonstrada com relação às instituições políticas. À guisa de conclusão, aponto para os desafios que reivindicações, no contexto da cultura política do consumo, colocam para a própria democracia.

\section{Fundamentos políticos da cultura do consumo}

O termo "cultura política" tem uma longa e controversa história. Sua origem é atribuída à Almond e Verba (1980) e Verba e Almond (1963), a partir da discussão sobre "civic culture". A essa abordagem, que considera de tradição conservadora, o cientista político José Álvaro Moisés (1992) apresenta a abordagem à esquerda, de tradição marxista, que se localiza em Antonio Gramsci e em sua concepção de hegemonia. 
O que é importante destacar, tendo em vista os objetivos deste artigo, é que em ambas as abordagens a ideia de cultura política se constrói a partir da "compreensão do papel da dimensão cultural e dos valores nos processos de legitimação política" (Moisés, 1992, p.4). Ou seja, o que está em jogo na definição do conceito é a compreensão das orientações subjetivas dos cidadãos e sua importância para certa estabilidade dos regimes políticos.

Ao cunhar o termo "cultura política do consumo", não pensei em filiá-lo a abordagens acadêmicas já sedimentadas. O termo surgiu a partir das minhas pesquisas no campo da cultura do consumo e da emergência de termos ligados ao campo da política, como os de "consumidor-cidadão" (Canclini, 2001); "política do consumo" (Streeck, 2013); "politics of consumption" (Bradshaw et al., 2013); "politização das corporações" (Barley, 2010), dentre outros. Assim, é na maneira como o político começa a aparecer no contexto da cultura do consumo que o termo ganha certo significado para mim. Mas é possível afirmar que a cultura política do consumo guarda uma proximidade com a concepção da cultura política, dado que o que se apresenta, de maneira geral, na concepção de cultura política, é uma tensão permanente do político, em função da "interação complexa do comportamento com o funcionamento das instituições democráticas, o que implica processos de socialização e re-socialização política..." (Moisés, 1992, p.5). Veremos como a socialização pelo consumo, ao longo do século XX - assim como o entrelaçamento entre consumo e política, a partir de certa democratização pelo consumo -, passou a tensionar cada vez mais esse processo.

A questão do político está presente desde a configuração inicial da cultura do consumo. Nos Estados Unidos, nas décadas iniciais do século XX, o trabalho da emergente profissão de Relações Públicas foi construindo a cultura do consumo não apenas a partir da ressignificação de questões políticas centrais da época - para fins consumistas (política do consumo) -, mas também a partir da relação que as corporações passaram a estabelecer com os governos, tanto do ponto de vista da constituição de lobbies (politização das corporações) como em busca da construção de suas imagens enquanto "civic assets", através da propaganda.

No caso da ressignificação de questões políticas para fins consumistas, o livro Propaganda, de Edward Bernays (1928) - considerado o criador das relações públicas -, é ilustrativo de como a cultura do consumo foi formatada, em grande parte, lançando mão de aspirações políticas que foram ressignificadas sob a lógica do consumo.

Mas os profissionais de relações públicas fizeram mais do que ressignificar questões políticas visando vender produtos. Construíram um novo conceito de política a partir da relação da democracia com um "estado da sociedade" (Rancière, 2014), relacionando consumo à democracia. Essa nova relação começou a se desenvolver por ocasião da Primeira Guerra Mundial. Segundo o historiador Roland Marchand, a experiência dos líderes empresariais, quando muitos deles tiveram participação ativa nos esforços de guerra, teve um profundo impacto em 
suas ideias de pensar "business as a public service" e de moldar a imagem da empresa como "associative state" (Marchand, 1998, p.88-9). Marchand mostra o papel fundamental que os profissionais de relações públicas tiveram em associar organizações e governo como indistinguíveis e inseparáveis. A comunidade de negócios entendeu rapidamente que "não apenas produtos, mas também políticas e ideias poderiam ser vendidas" (ibidem, p.89).

O uso político do consumo contou também com os próprios interesses governamentais. Os dirigentes políticos começaram a entender que, pelo consumo, seria possível transformar "cidadãos potencialmente perigosos para a ordem estabelecida, em dóceis consumidores" (Gorz, 2005, p.49), podendo-se evitar, assim, qualquer tipo de conflito social. Herbert Hoover, presidente americano à época dos grandes experimentos de Bernays, chegou a afirmar que esse havia conseguido produzir "incansáveis máquinas de felicidade" (apud Gorz, 2005).

A relação positiva entre política, organizações e consumo persistiu e até se intensificou após a Segunda Guerra Mundial. A guerra fria foi também uma guerra de imagens, na qual as grandes empresas foram parceiras fundamentais do governo na defesa de um modelo econômico, social e cultural assentado no consumo. Foi assim que se constituiu toda a luta ideológica do capitalismo em oposição ao socialismo.

Liberdade de escolha - que paulatinamente ganhava os contornos de uma democracia de mercado - foi a imagem capitalista que se contrapôs à igualdade socialista. O objetivo era mostrar que, além de possuírem carros e bens de consumo, os cidadãos também tinham liberdade de opinião e de ir e vir. Assim, entre aquelas que ficaram conhecidas como as "décadas douradas" do capitalismo (1945-1975), houve um incremento do consumo, formatando o que o filósofo francês Gilles Lipovetsky $(2007$, p.32) considerou "a fase mais pura da sociedade de consumo", tendo em vista que ela não apenas prolongou os processos inventados no estágio precedente - e o expandiu para a grande massa -, mas porque ela se constitui como "uma imensa mutação cuja radicalidade, instituidora de uma ruptura cultural, jamais será sublinhada o bastante" (ibidem - grifo meu).

No final da década de 1960, entretanto, esse equilíbrio começou a ser desestabilizado, quando surgiu uma onda de questionamentos que ficou configurada como um movimento contracultural que atingiu, ao mesmo tempo, governos e organizações. Tratava-se de uma forma de protesto majoritariamente constituída por jovens e trabalhadores, em especial nos países desenvolvidos da Europa e nos Estados Unidos, que rechaçava toda forma de poder institucional, como a família, a universidade, o Estado, a fábrica.

Assim, se havia uma recusa à disciplina das fábricas e uma reivindicação pela redução da carga de trabalho e por melhorias salariais, havia igualmente, em especial entre os jovens, uma recusa à aridez de uma forma de vida sustentada por aquilo que um dos inspiradores do movimento contracultural, Frank Zappa, 
considerava "padrões obsoletos e restritivos de pensamento, moda e etiqueta social" (Goffman; Joy, 2007, p.283). Vê-se que o foco da crítica não era o consumo em si, mas ao consumo de massas de produtos padronizados, que estava diretamente atrelado a um modo de trabalho e de vida cada vez mais burocratizado, hierarquizado e conformista.

Havia, também, a luta pelos direitos civis e a recusa da guerra, pois o que se propunha era o resgate da "cultura como política”, ideal que já estava se perdendo em meio a uma crescente "cultura do entretenimento" (ibidem, p.299). Por isso, era um movimento guiado pela crença de que seria possível fazer a revolução através da cultura artística "autêntica", dando "todo poder à imaginação", conforme um dos slogans do movimento francês que ficou conhecido como Maio de 68.

Da lógica interna do funcionamento do capitalismo, o que havia era uma estagnação econômica e uma crise política: estava claro que o crescimento já não poderia mesmo se dar a partir de produtos de consumo duráveis, cujo mercado já estava saturado; assim como era evidente a necessária quebra da força política da classe trabalhadora, que havia se tornado muito poderosa e reivindicava cada vez mais sua participação nos lucros e na direção das empresas (Harvey, 2010).

Tudo somado, hoje se sabe no que resultou a busca de resolução da crise do capitalismo com a revolução contracultural iniciada nos anos 1960: no plano cultural, chegou-se à assimilação da crítica pela cultura de negócios, o que o crítico cultural americano Thomas Frank (1997) nomeou "the conquest of cool"; no plano político-econômico, houve uma transformação radical na forma de governo e no tipo de reestruturação produtiva do trabalho e suas relações.

No contexto político-econômico, foram tomadas algumas medidas - com forte suporte governamental, como estímulo à imigração de mão de obra barata -, a fim de minar a força de trabalho que, na década de 1960, era bem organizada, razoavelmente bem paga e politicamente influente. Tudo isso foi apoiado pela ascensão de governos neoliberais como o da primeira-ministra britânica Margaret Thatcher, em 1979, e do presidente americano Ronald Reagan, em 1981, além dos governos que serviram de "laboratório" para o projeto neoliberal na América do Sul, incluindo o Brasil (Harvey, 2010).

Nesse contexto, as grandes organizações tornaram-se artífices de uma profunda revolução cultural que levou a própria cultura a se tornar a principal mercadoria do capitalismo (Jameson, 1991), respondendo de forma ressignificada a muitas das reivindicações da contracultura. Segundo Frank, nos anos 1960, uma parte da cultura de negócios já estava absolutamente em sintonia com as reivindicações contraculturais por mais criatividade e menos conformismo. Foi por isso que muitas das críticas puderam ser absorvidas por uma cultura de consumo que também se reinventava a partir do seu próprio objeto de ataque. Em outras palavras, o movimento contracultural da década de 1960 deu o combustível necessário para que o capitalismo se reinventasse. 
Se a contracultura foi tão rapidamente assimilada é porque, segundo o filósofo francês Dany-Robert Dufour (2013), a geração nascida a partir das décadas de 1930 foi aquela que viveu os primeiros grandes efeitos de uma cultura do consumo já estabelecida. Teria sido daí que resultou a juventude das décadas de 1950-1960, que já protestava no "espírito do gozo"; ou seja, na lógica da liberação dos desejos, ainda acreditando na ideia de uma "cultura autêntica" e de que ela era contrária à cultura de consumo quando, na verdade, sua reivindicação já era produto dela.

No espírito desse "hip consumerism", o investimento na formatação de sujeitos como consumidores se expandiu nas décadas seguintes, a fim de estruturar suas formas de pensar, de se relacionar, de viver, a partir dos significados do mundo das mercadorias, em especial, a partir da comercialização de imagens e marcas. Se isso funcionava no nível do imaginário publicitário é porque as organizações já tinham assumindo a esfera pública da cultura. Ao fazer a crítica à privatização do espaço público pelas grandes corporações e suas marcas globais, Klein aponta justamente o momento do branding dos anos 1990 como aquele no qual as corporações deixaram de buscar inspiração no reino da representação cultural e passaram à tarefa de se produzirem como cultura. Se, por exemplo, na fase anterior, a meta da Coca-Cola era veicular comerciais com atores mirins bebendo Coca-Cola, nesse novo estágio, o que importava era que os estudantes debatessem conceitos para a próxima campanha da Coca-Cola; se, antes, as marcas se colavam às obras artísticas a fim de se promoverem, agora, elas davam o lastro a eventos de obras de arte. Assim, "o efeito do branding avançado é empurrar a cultura que a hospeda para o fundo do palco e fazer da marca a estrela. Isso não é patrocinar cultura, é ser a cultura" (Klein, 2002, p.53). É nesse ponto que a cultura do consumo alcança o sonho - pelo avesso - da contracultura dos anos 1960: realiza a cultura como política.

\section{Os anos 1990: do repúdio às marcas ao acolhimento da empresa-cidadã}

No final dos anos 1990, quando o processo de reestruturação das grandes organizações empresariais mundiais já havia se sedimentado, e quando começou a ficar mais claro o que havia acontecido no mundo do trabalho após a ofensiva neoliberal, a política da resistência voltou a aparecer sob a forma de protestos que ficaram conhecidos como antiglobalização. Mas definir tais processos dessa forma não faz jus ao que eles, de fato, representavam. Esses movimentos não eram contra a globalização per se, mas ao tipo de globalização que se estava praticando, através da terceirização da força de trabalho em partes do mundo onde a mão de obra era mais barata; assim como, à expansão da forma-mercadoria que ocupava cada vez mais a esfera pública da cultura; além da privatização de serviços públicos essenciais como saúde, educação, transporte.

Foi com esse tipo de globalização e um capitalismo que se via sem avesso, em razão da crise do projeto socialista advinda com a queda do muro de Berlim 
no final dos anos 1980, que as grandes corporações começaram a investir na gestão global de suas marcas. Esse processo também foi fortemente influenciado pela financeirização da economia, que levou as corporações a buscarem agregar valor às suas marcas como parte de uma lógica maior de busca de valorização fictícia do capital da empresa (Gorz, 2005; Fontenelle, 2002).

É nesse contexto que emergem os movimentos anticorporativos, que se caracterizaram como protestos que colocavam as corporações no centro da insatisfação contra um estado de coisas. Para Klein, foram movimentos de crítica às marcas globais, suas corporações e, no limite, contra o próprio capitalismo. Em suas palavras, "o que a mídia corporativa insistiu em chamar de movimento anti-globalização não era nada disso. No sentido reformista, era um movimento anti-corporativo; no sentido radical, era anticapitalista..." (Klein, 2009, p.xviii). Sendo anticorporativos, esses movimentos visavam atingir grandes marcas globais, na medida que suas corporações teriam perdido a lealdade e o respeito do cidadão, na medida em que haviam, segundo Klein, abandonado sua função como empregadores para se guiar por uma gestão baseada em marketing. Dessa perspectiva, o que esses movimentos reivindicavam era um comprometimento maior das corporações na geração de empregos, no cuidado ao meio ambiente, ao comércio justo e a relações de trabalho mais humanas.

$\mathrm{Na}$ perspectiva radical, esses movimentos foram compreendidos como lutas globais de resistência que desafiavam a concepção marxista clássica da luta de classes. Sendo apartidários e com uma pauta ampla de reivindicações - que englobava batalhas pós-coloniais, indígenas, movimentos feministas, negros, dentre outros -, tais protestos defendiam a capacidade de articulação da sociedade civil no lugar de uma política centrada no Estado. Isso produziu amplo debate acadêmico em torno dos alcances e limites da democracia representativa ou de uma possível sociedade civil global que pudesse avançar nas possibilidades de uma crítica radical ao presente (Salecl, 1994; Magala, 2006; Kingsnorth, 2005; Carducci, 2008; Jubas, 2007; Kozinets; Handelman, 2004; Trentman, 2007).

Se, por um lado, as críticas às grandes marcas não chegaram a abalar seus alicerces, gerando apenas o estranho fenômeno de essas continuarem a ser desejadas e consumidas, por mais que fossem expostas ao escrutínio público (Böhm; Batta, 2010); por outro, acabaram servindo de inspiração para o desenvolvimento de um novo momento na cultura de consumo, com o nascimento da "empresa-cidadã". A “culture jamming", por exemplo, apontada por Klein como um dos principais instrumentos de crítica dos movimentos anticorporativos, foi criticada por Carducci (2006) como tendo tido um poderoso efeito inverso de se tornar uma espécie de sinalizador dos "defeitos da marca" e, com isso, ajudado, ironicamente, a "reabilitar o sistema de mercado que, muitas vezes, a culture jamming propunha transcender, podendo, inclusive, servir para melhorar algumas 'falhas de mercado' do sistema global”. Dessa Perspectiva, culture jamming pode ser compreendida como "uma forma ad hoc de marketing social [...] uma 
maneira de propor mudanças de mentalidade e de comportamento" (Carducci, 2006, p.116, 119).

As corporações se deram conta de que não poderiam atuar apenas no plano da imagem. Era preciso criar uma cultura política do consumo a fim de que pudessem marcar sua presença positiva no mundo, através de ações no espaço público. Como visto, isso já vinha sendo feito na reformulação da cultura do consumo pós revolução contracultural dos anos 1960 mas, até a explosão dos movimentos anticorporação, o investimento das corporações era fundamentalmente focado no campo cultural. Dessa vez, o campo de batalha passou a ser o político, com as grandes marcas tomando a dianteira no atendimento à demanda reformista contida nos movimentos antiglobalização e ressignificando o caráter mais radical dos protestos.

Isso levou a um movimento ruidoso sobre responsabilidade social empresarial que, somado à emergência do discurso da crise ambiental, deu combustível novo para que as corporações assumissem o papel de guardiãs do mundo social, ambiental e político. Obviamente, a discussão acerca do papel social das empresas, e da própria noção de responsabilidade social, é anterior a esse momento. Mas o que se aponta aqui é que, nesse estágio, a responsabilidade social se renova para se tornar algo estrategicamente atrelado ao "marketing social e ético" (Carducci, 2006).

Para Robert Reich (2008, p.171), professor de políticas públicas da Universidade da Califórnia, "a responsabilidade social das empresas se transformou em expectativa de resposta para o paradoxo do capitalismo democrático". Mas o autor lembra que as empresas não são cidadãs; são um conjunto de papéis e contratos. E argumenta que esse tipo de movimento poderia destruir a própria democracia, já que "a fronteira entre democracia e capitalismo fica obliterada quando as empresas parecem assumir responsabilidades sociais ou quando elas utilizam a política para reforçar ou para manter suas posições competitivas" (ibidem, p.229).

O que Reich aponta é que esse movimento acaba se esgotando também no plano da imagem, dado que sua capacidade de promover mudanças políticas é limitada. E, ainda segundo o autor, sob o desafio de assumirem a liderança em questões sociais e ambientais, as organizações, na verdade, estariam evitando que as autoridades públicas "façam muita coisa em relação ao meio ambiente e em qualquer outra área que envolva ameaças a seus interesses primordiais como organizações de negócios" (ibidem, p.172). Estariam, assim, no melhor dos mundos: ao abraçarem a causa da responsabilidade social, projetam uma boa imagem; enquanto, internamente, pressionam, com os seus lobistas, contra leis e regulamentos contrários aos seus interesses. Por isso, Reich propõe que os cidadãos, em especial americanos e europeus - na medida em que vivem em áreas prósperas e importantes - ajam com mais vigor em busca da realização das leis vigentes em seus países, propondo a elaboração de leis mais eficazes na defesa 
do meio ambiente ou da justiça social. E dá um alerta: “os cidadãos desses países grandes e poderosos que se consideram capazes de exercer maior impacto ao pressionarem as empresas a serem virtuosas, em vez de recorrerem ao processo democrático para forçá-las a mudar seu comportamento, estão simplesmente errados" (ibidem, p.173).

Talvez Reich já tivesse se dado conta de que se desenhava uma nova forma de política conduzida pelo mercado. Pois, se no nível cultural, as corporações trabalhavam no polimento de suas marcas, no nível macro, ocorria uma forma de "política intrusiva" (Dufour, 2008), que faria as corporações assumirem cada vez mais o papel de política do mundo. Essa tarefa foi facilitada no contexto da reestruturação do Estado sob o governo neoliberal, que levou as grandes corporações, em especial através de fundações e organizações não governamentais, a assumirem esse lugar de "cuidadoras" do social, do cultural, do político, sob o rótulo da "responsabilidade social corporativa" ou da "cidadania empresarial". Esse novo formato da cultura do consumo foi reforçado, nessas primeiras décadas do século XXI, pela crise ambiental e econômica, bem como por uma mudança radical na mentalidade "política" do cidadão, que passou a se pensar e se comportar cada vez mais como consumidor. E é nesse duplo movimento das corporações e dos consumidores - que localizo o que estou denominando de "cultura política do consumo".

\section{A "política do consumo" e a crise da democracia representativa}

Passada mais de uma década do apogeu dos movimentos anticorporação, os movimentos de protestos que emergem nos dias atuais ocorrem de maneira difusa, pois "não existe um único objetivo real perseguido pelos manifestantes. O que a maioria compartilha é um sentimento fluido de desconforto e descontentamento que sustenta e une demandas particulares" (Zizek, 2013, p.101).

Mas, de certo modo, com exceção do movimento "Occupy Wall Street" que, como o próprio nome já deixa claro, é uma manifestação contra o mercado, mais precisamente, contra a força do capitalismo financeiro,${ }^{6}$ os demais movimentos se insurgem contra ditaduras ou governos eleitos.

No caso dos protestos em países democráticos, a característica marcante é a raiva que os manifestantes demonstram contra os seus governos, apontando para uma crise da democracia representativa. Essa é a perspectiva do sociólogo alemão Wolfgang Streeck. Segundo o autor,

[...] o gerenciamento político do capitalismo democrático tem caído acentuadamente nos últimos anos, mais em alguns países do que em outros, sendo um dado importante do emergente sistema político global. Como resultado, os riscos continuam crescendo, tanto para a democracia, quanto para a economia. Desde a Grande Depressão, os líderes políticos nunca tiveram que se defrontar tanto com as incertezas quanto nos dias atuais. Nesse cenário, a democracia está em risco tanto quanto a economia, se não mais. (Streeck, 2011, p.24-5) 
Entre as razões que levaram à crise da democracia representativa há uma apontada por Streeck que interessa diretamente aos propósitos deste artigo. O autor considera que, ao longo do século XX, começou a se dar uma passagem da forma de pensar do cidadão para a do consumidor, decorrente das transformações nos padrões de consumo. A reestruturação produtiva, ocorrida a partir da década de 1970, gerou uma oferta de produtos e serviços diferenciados e essa diferenciação acabou estimulando o desejo crescente por mais diferenciação que atendesse as preferências de cada consumidor. Diz o autor que o consumidor começou a se disponibilizar a pagar e, portanto, a trabalhar ou até mesmo a tomar dinheiro emprestado, a fim de se inserir nesse novo modelo de consumo.

Streeck argumenta que esse processo de socialização mudou a maneira de o indivíduo se conectar aos outros, de definir seu lugar no mundo. As extensas possibilidades de consumo levaram as pessoas a conceberem "um ato de compra como um ato de autoidentificação e autoapresentação, que as diferenciam de certos grupos sociais e as unem a outros". Comparada a modos mais tradicionais de integração social, esse novo tipo de socialização permitiu "que as identidades sociais se tornassem estruturadas por laços mais fracos e mais frouxos". Na socialização pelo consumo, não há necessidade de negociação ou de ceder, se houver dinheiro a pagar. Assim, "a socialização pelo consumo é monológica e não dialógica, voluntária e não obrigatória, individual e não coletiva" (Streeck, 2012, p.35-6).

É a partir dessa perspectiva que o autor propõe o termo "política do consumo" para pensar a passagem para um novo tipo de política baseada no mercado; assim como para apontar a crise da democracia representativa. Isso porque a expansão desse novo modelo de consumo acabou gerando um efeito perverso: os cidadãos começaram a exigir do Estado o mesmo tipo de atendimento que passou a ter no mercado de consumo. Streeck aponta tal impossibilidade considerando as características próprias do serviço público, que é oferecer o que as pessoas necessitam e, portanto, oferecer o mesmo coletivamente. Por isso, diz o autor, "a condição de cidadão é, por sua própria essência, menos confortável que a condição de consumidor" (ibidem).

Tal fato levou a um contínuo descrédito da esfera pública, favorecendo também uma perspectiva social positiva para os processos de privatização do público que começaram a ocorrer. Mas o pior efeito disso, diz Streeck, é que mudou a natureza da própria política. Assim, conclui o autor:

[...] a reestruturação do consumo destinada a restabelecer a dinâmica da acumulação capitalista possibilitou - na verdade, estimulou e cultivou - atitudes e expectativas por parte dos consumidores-cidadãos que começaram a se irradiar para o que restava da esfera pública. ${ }^{7}$ Diante de um sistema político carente de legitimidade e de recursos materiais, reduzido à política como entretenimento (ou politainment, como já se diz em inglês), as classes mais baixas passam a seguir o exemplo da geração mais jovem. Se abstêm de votar, em números cada 
vez maiores, recusando-se a participar mesmo simbolicamente do que poderia ser o seu último recurso na busca de uma vida melhor. Na Europa Ocidental, o cenário é cada vez mais parecido com o dos Estados Unidos. (Streeck, 2013)

Tal recusa pode não se manifestar apenas na ausência do voto, mas nos tipos de protestos que se voltam contra certo modo de fazer política, qual seja: em certas formas de manifestações nas quais se percebe o desencanto com a forma atual de democracia. Foi isso que acabou aparecendo nas jornadas de junho de 2013, no Brasil, e que ficou configurado como o essencial dessas manifestações. Voltemos ao Brasil.

\section{Antes e depois de junho: considerações sobre a cultura política do consumo no Brasil}

No cenário de uma globalização não apenas econômica, mas igualmente cultural, o Brasil tem apresentado manifestações da cultura política do consumo em seu duplo movimento, ou seja, tanto do lado da incorporação da política pelas empresas quanto do lado da reivindicação promovida pela "política do consumidor".

No plano político mais amplo, o Brasil viveu processos intensos de privatização de serviços e espaços públicos a partir da década de 1990, seguindo o ideário neoliberal que mobilizou tais espaços necessários para a expansão do capital. Esse processo ensejou uma literatura crítica específica sobre o país, sendo definido como "era da indeterminação" (Oliveira; Rizek, 2007), em razão do "desmanche neoliberal" e da consequente destituição do público a que o país havia passado, o que levou os processos de gestão empresarial e a racionalidade técnica a se sobreporem à política (Paoli, 2007). Foi nesse mesmo período que surgiram também as grandes fundações empresariais, assim como uma imensa rede de associações privadas sob o título de organizações não governamentais, radicalizando a ideia de "governança" no terreno da política. Ao mesmo tempo, o Estado brasileiro passou por processos de transformação, através da implantação de processos de gestão que o fizesse funcionar segundo as regras de eficiência e produtividade do mundo privado, no atendimento ao seu "cidadão-consumidor".

Hoje, já pululam organizações, institutos e movimentos centrados na construção de um capitalismo mais "consciente" e de empresas mais cidadãs, voltadas a serem social, cultural e ambientalmente responsáveis por questões que eram historicamente associadas ao domínio do que é público.

Da perspectiva da "política do consumidor", no sentido discutido por Streeck (2013), são multifacetados e complexos os espaços nos quais é possível se buscar entender esse fenômeno. No Brasil, a lógica de que o que é privado é melhor prevalece. Certamente, isso é fortalecido pela má qualidade dos serviços públicos. Mas, mais que isso, serviços privados de saúde e educação, assim como a posse do automóvel, tornaram-se não apenas necessários - em razão de uma "falência" do serviço público -, mas passaram a representar um sinal de ascensão 
social. Não por acaso, ter acesso a hospitais e escolas "de grife" aparecia como aspiração em cartazes nas manifestações de junho, como os que diziam quererem "hospitais padrão Fifa". Pode-se aventar que, nesse aspecto, havia uma crítica aos altos investimentos do governo na Copa do Mundo de 2014, em razão do que seriam as exigências da Fifa. Mas a minha hipótese é que, para além dessa crítica pontual, tais reivindicações já apontam para uma aspiração a um tipo de serviço comparável à rede privada.

Claro está que entre um extremo e outro - da má qualidade da rede pública de saúde a hospitais "padrão Fifa" - há uma enorme diferença. Com isso, quero dizer que a crítica ao não atendimento desses serviços públicos é absolutamente legítima. E se fossemos enveredar por essa discussão, caberia toda uma leitura sobre o papel do Estado nesse contexto. Mas a questão que quero apontar aqui é que a reivindicação de hospitais "padrão Fifa” já indica uma demanda condizente com o consumidor-cidadão; que revela um imaginário em torno do sonho consumista, que é poder comprar o que o dinheiro pode pagar. Trata-se, no caso, de uma subjetividade privatizada que, no limite, está mais próxima do sonho do plano de saúde particular do que de melhoria do setor público.

Essa "política do consumo" também pode ser ilustrada pela emergência de dois outros fenômenos que, de certa forma, se relacionam com as jornadas de junho: os "rolezinhos" e o movimento musical "funk ostentação".

Os rolezinhos são agrupamentos de jovens da periferia das grandes cidades que se auto-organizam via redes sociais. Esse fenômeno, de encontrar-se em grupo para "curtir e se divertir", é bem anterior às manifestações de junho, mas ficaram caracterizados como parte desse movimento maior, ao se destacarem no segundo semestre de 2013 e, especialmente, nos últimos meses daquele ano, quando passaram a ocorrer em regiões centrais de cidades como São Paulo e em shoppings considerados de elite.

Para Gohn (2014, p.88), trata-se de outra forma de manifestação dos jovens das periferias, que apresentam "uma agenda oculta implícita de demandas - a do direito ao lazer, à diversão, aos templos do consumo. Já que não há centros culturais, espaços para esportes, praças e parques públicos nas periferias, ou políticas públicas culturais para essas camadas, os shoppings entraram na mira" (grifo meu).

Já Caldeira (2014) associa os rolezinhos aos protestos de junho. A autora compreende esse movimento como a encarnação de uma experiência típica das cidades modernas na disputa pelo controle do espaço público. Lembra que o fenômeno, no Brasil, data da década de 1990, quando ao mesmo tempo em que despontava um desejo crescente dos jovens dos bairros periféricos em circular pela cidade, assistia-se a várias formas de produção cultural que evidenciavam a realidade cotidiana da periferia, marcada por exclusão e violência. Entre essas manifestações, encontrava-se o rap, caracterizado por uma forte crítica social, em tom agressivo e com "claro antagonismo de classe e de raça" (Caldeira, 
2014 , p.15). Embora herdeiro desse movimento, os rolezinhos de 2013 requerem, segundo Caldeira, que se busque uma nova articulação entre os elementos que constituem esse fenômeno - quais sejam, as questões de circulação, tensões de classe e de raça- e, agora, de consumo. Isso porque "a produção cultural mais próxima a eles é o funk ostentação" (ibidem).

De fato, o consumo tem sido o foco principal das músicas que compõem o funk ostentação, um movimento que se iniciou na baixada santista, cujas primeiras manifestações datam de meados da década de 1990, mas que explode nas periferias paulistas em meados de 2000 , com cantores fazendo apologia ao consumo de produtos com marcas de luxo. Esse momento coincide com o do crescimento histórico do consumo na periferia de São Paulo que, entre 2005-2010, cresceu 61,6\%, segundo dados do Instituto Data Popular (Moreira, 2011). ${ }^{8}$

Lançando mão da mídia virtual, o funk ostentação popularizou-se, também, entre consumidores ricos de São Paulo, com seus principais cantores fazendo shows em casas noturnas de bairros nobres da capital paulistana e ganhando dinheiro suficiente para pôr em prática tudo aquilo que defendem em suas músicas e videoclipes, ou seja, o consumo de produtos e marcas de luxo (Manso, 2013; Ortega, 2012).

O funk ostentação era a referência direta dos jovens que participaram dos rolezinhos de 2013. Ao cantarem suas músicas, quando adentravam os shoppings, os jovens deixavam explícito que o espaço no qual desejavam circular era o espaço do consumo. Para Caldeira (2014, p.16), os rolezinhos contemporâneos e o funk ostentação

[...] revelam transformações importantes na estrutura do consumo geradas por mudanças na distribuição de renda e pela expansão do mercado de bens de consumo individual. A expansão do consumo é parte fundamental do projeto de diminuição da desigualdade social que vem orientando as políticas públicas brasileiras há mais de uma década. No Brasil, ascensão social tem sido medida pelo consumo.

É por isso que, para Caldeira, não há como desvincular os rolezinhos dos protestos de junho. Para a antropóloga, ambos os movimentos foram protagonizados por jovens e problematizaram os mesmos temas que estavam enraizados em seu cotidiano, dentre eles a reivindicação pelo direito de circular em uma cidade que busca segregar. Não por acaso, lembra que são movimentos que "contestam autoridades constituídas e modos de regulação e separação preexistentes" (ibidem, p.19), E que só se tornaram visíveis no momento em que foram reprimidos pela polícia.

Nesse sentido, é interessante mencionar a música "o gigante acordou", que MC Daleste - um dos principais expoentes do funk ostentação - compôs sobre as manifestações de junho, e que foi veiculada em videoclipe. ${ }^{9}$ A música também enfatiza o outro slogan dos protestos - o "vem pra rua" -, assim como a crítica ao governo, com ênfase na insatisfação com o aumento de impostos e 
o preço da condução. E ao falar de sonhos destruídos e da perda da crença nos políticos, defende que o movimento era "por direitos e não por centavos".

Sem dúvida, as jornadas de junho foram mais amplas e complexas, até mesmo porque envolveram diferentes momentos, atores e demandas. Mas é possível associar os rolezinhos e o funk ostentação às manifestações. Sobretudo, é possível tomá-los como ilustrações para o tema que estou desenvolvendo, o da cultura política do consumo e das (im)possibilidades de resistência nesse contexto. A democratização pelo consumo está na base de movimentos como os do rolezinho e do funk ostentação. ${ }^{10}$ Não é possível afirmar que esteja na base das jornadas de junho, embora tenhamos visto como, na forma como se manifestaram, há elementos que apontam para momentos nos quais a "política do consumo" se sobressai; assim como vimos como é possível as grandes marcas resignificá-los a partir dessa lógica. Na cultura política do consumo, a ideia de democracia passa, necessariamente, pelo consumo. Tal questão também se deixa entrever no que ficou mais evidenciado nas jornadas: a crítica a uma forma de democracia representativa.

\section{À guisa de conclusão: paradoxos de uma manifestação democrática que põe em causa um modo de exercício da democracia}

Retomando a associação entre a cultura política do consumo com a noção teórica de cultura política, discutida anteriormente, convém lembrar que nossa abertura democrática andou em paralelo ao desenvolvimento de uma cultura política baseada na desconfiança do mundo da política representativa. Segundo Lima $(2013$, p.90),

[...] pelo menos desde que a televisão se transformou em "mídia de massa" hegemônica no Brasil, a cultura política que vem sendo construída e consolidada no Brasil tem sido a de permanentemente desqualificar não só a política em si como seus atores. E é no contexto dessa cultura política que as gerações pós-ditadura foram formadas, mesmo não sendo usuárias diretas da velha mídia.

Embora nossas instituições políticas em nada tenham ajudado a desfazer esse viés midiático, Lima (2013, p.90) lembra bem que "independente das inúmeras e legítimas razões que justificam a expressão democrática de uma insatisfação generalizada por parte de uma parcela significativa da população brasileira, não se pode ignorar a construção de uma cultura política que desqualifica sistematicamente as instituições políticas e os próprios políticos" (grifo meu).

Sem dúvida, do lado da interpretação midiática, houve uma apropriação permanente das reivindicações a partir da perspectiva da crítica ao governo. Para Secco (2013), isso ficou mais evidente quando as manifestações passaram do seu primeiro momento, caracterizado por uma atitude apartidária do Movimento Passe Livre (MPL), para um protesto de massa, que apresentava uma franca atitude antipartidária, indicando uma insatisfação e até mesmo um repúdio às instituições políticas. Esse foi o instante em que, segundo Celso Frederico (2013, p.248), a cobertura televisiva procurou "imprimir um determinado sentido ao acontecimento". 
Mas vimos como diferentes leituras acadêmicas desenvolveram uma interpretação semelhante no que diz respeito à convicção de uma clara insatisfação manifestada nas jornadas de junho quanto à democracia representativa. Em outras palavras, há uma espécie de consenso, embora por razões ideológicas bem diferentes, sobre o fato de que o que foi manifestado nas jornadas foi uma espécie de desilusão, ou até mesmo de rejeição, à democracia representativa.

Esse consenso pode indicar diferentes saídas. Há, certamente, a perspectiva de que a frase "vocês não nos representam", tão presente nos protestos, aponte para novas aberturas democráticas, novas formas de fazer política que resgatem a ideia de cidadania em sentido pleno, já que a democracia, de fato, não se reduz às suas instituições.

Mas, a partir da perspectiva da constituição em curso de uma cultura política do consumo, é possível que isso aponte para um horizonte de expectativas mais aderente à politização das corporações. Como vimos, no contexto publicitário, já houve a busca de uma ressignificação dos protestos sob o pano de fundo das grandes marcas globais, indicando como as grandes corporações são capazes de dar uma resposta à altura do problema; enquanto, da perspectiva midiática, o governo é retratado ora como corrupto, ora como incapaz.

Tal cultura política se apresenta como solo fértil para a política do consumo. Mas até que ponto esse formato cultural consegue se sustentar em um contexto de crise política radical? Analisando esse processo no Reino Unido, Burgess (2001, p.114) indica que essa nova cultura do consumidor-cidadão, que vem sendo cada vez mais politizada discursivamente pelas instituições, está sendo difícil de ser acomodada tanto pelo mundo dos negócios quanto pelo governo, e que está difícil "to see how society can be re-energized by demanding consumer". O autor argumenta que, na luta por darem maior autoridade e legitimidade ao consumidor, as organizações tem "institucionalizado impulsos que são suscetíveis de, no longo prazo, intensificar a desconfiança social" (ibidem). Passada mais de uma década, e com os recentes conflitos sociais que vêm emergindo, tende-se a dar razão a Burgess.

Esse ponto se liga a outro diretamente relacionado aos objetivos deste artigo, relativo às formas de crítica que não seriam passíveis de serem assimiladas pela cultura de consumo. Os novos tipos de protesto que se radicalizaram no Brasil, desde junho de 2013, que passaram a ser conhecidos como movimentos dos "black blocs", vêm apontando na direção de um "resto" não assimilável pelo mercado. Caracterizando-se por destruir símbolos da cultura do consumo, tais protestos poderiam ser indicados como componentes de um terceiro momento das manifestações de junho, embora estivessem presentes desde o início.

Tais movimentos requerem uma análise própria e substantiva que não foi feita aqui, mas é possível apontar que, dentro da reinscrição dos protestos de junho sob a lógica do consumo, se no plano do imaginário essa lógica se oferece como um dispositivo capaz de resolver essa crise de legitimidade política - ou, 
pelo menos, empurrá-la mais um pouco -, os black blocs apontam para o que pode restar caso isso não funcione. Uso dispositivo no sentido foucaultiano, reinterpretado por Agamben (2010, p.29): "a rede que se estabelece entre discursos, instituições, edifícios, leis, medidas de polícia, proposições filosóficas, etc." com uma função eminentemente estratégica. Agamben (2009, p.44-6) diz ainda que

[...] na raiz de todo dispositivo está um desejo demasiadamente humano de felicidade, e a captura e a subjetivação deste desejo, numa esfera separada, constituem a potência específica do dispositivo [...] todo dispositivo implica um processo de subjetivação, sem o qual o dispositivo não pode funcionar como dispositivo de governo, mas se reduz a um mero exercício de violência.

Este artigo mostrou o quanto a cultura do consumo tem sido um poderoso dispositivo de captação de desejos que são ressignificados sob a lógica do mercado; assim como vem se formatando de forma coerente com a ideia de que "o que define os dispositivos com os quais temos que lidar na atual fase do capitalismo é que estes não agem mais tanto pela produção de um sujeito quanto por meio de processos que podemos chamar de dessubjetivação" ou, no máximo, à recomposição de um sujeito de forma apenas "larvar" e "espectral" (ibidem, p.47). Seriam os black blocs uma representação desses novos sujeitos?

\section{Notas}

1 Trata-se de um movimento apartidário, fundado nacionalmente em 2005, com a pauta inicial de defesa da gratuidade do transporte público para o estudante, estendendo-se posteriormente para a conquista da tarifa zero para toda a população. Nos protestos de 2013, no entanto, a reivindicação era pela eliminação do aumento das passagens de ônibus feito naquele mesmo ano.

2 Para ver a subversão da campanha da Fiat, consultar: <https://www.youtube.com/ watch?v=iGai5q27pUg>.

3 Para ver os dois vídeos oficiais das campanhas Fiat e Johnnie Walker, consultar: <http:// www.meioemensagem.com.br/home/comunicacao/noticias/2013/06/18/Manifestacoes-incorporam-slogans.html\#ixzz2skxynMm2>.

4 Não por acaso, no vídeo que subverte as imagens do comercial Fiat, sob o pano de fundo da música "vem pra rua", aparecem imagens de ônibus absolutamente lotados, com pessoas penduradas na porta do coletivo. Ermínia Maricato lembra, com propriedade, o papel que o governo teve nesse processo, já que "há mais subsídios para a circulação de automóveis do que para o transporte coletivo. A prioridade ao transporte individual é complementada pelas obras de infraestrutura dedicada à circulação de automóveis" (Maricato et al. 2013, p.25).

5 Segundo Dufour (2008), o termo governança surgiu dos think tanks de inspiração neoliberal e a generalização do seu uso, a partir da década de 1990, não seriam fruto do acaso. Suas origens estão na expressão anglo-americana corporate governance e sua entrada na política é indicativa do processo de gerenciamento do público no qual "é de interesse público tudo o que interessa ao mercado" (Paoli, 2007, p.239). 
6 Embora, para o geógrafo David Harvey (2012), o movimento “Occupy” seja bem mais abrangente, caminhando para envolver "todas as pessoas jogadas na miséria e unir os trabalhadores criativos e artistas cujos talentos são transformados tantas vezes em produtos comerciais pelo grande poder do dinheiro", o que tem ocorrido é que o movimento vem sendo ressignificado como uma crítica ao "capitalismo ruim", que seria o capitalismo financeiro e que, portanto, seria preciso um retorno às bases produtivas e sociais do capitalismo. Esse é um contexto favorável ao discurso das empresas-cidadãs.

7 Walsh (1994) aponta que a questão da "escolha do consumidor" foi profundamente influenciada pela política neoliberal da era Thatcher. Opinião similar tem o sociólogo Adam Burgess (2001) que, a partir de uma análise no contexto britânico e americano, complementa sua análise indicando o quanto a cultura do consumo desses países, a partir dos anos 1980, foi moldada a partir da desregulamentação proposta pela reforma neoliberal que, em compensação, provocou a elevação da capacidade de mobilização do consumidor em resposta às incertezas percebidas no mercado desregulado. Assim, conclui Burgess (2001, p.110-11): “o respeito desfrutado pelo ativismo do consumidor é consequência do declínio das formas tradicionais de engajamento político e da erosão simultânea de confiança do público na autoridade convencional. As organizações de consumidores reconhecem que o crescimento de sua influência está enraizada na expansão de desconfiança”.

8 Dados sobre o funk ostentação aqui relatados foram extraídos dos artigos citados no texto e, também, do documentário Funk ostentação - o filme (Disponível em: <http://vimeo.com/5367907l>).

9 MC Daleste foi assassinado em julho de 2013, pouco antes de gravar o videoclipe que, até esta data, já teve 13.718.410 visualizações (Disponível em: <https://www. youtube.com/watch?v=r3tavFBcH4E $>$. Acesso em: 14 jan. 2015).

10 Enfatizei os rolezinhos e o funk ostentação em razão das afinidades que esses guardam com as Jornadas de Junho - ilustração maior do artigo para pensar as (im)possibilidades da crítica no contexto da cultura política do consumo. Mas seria possível apontar outros fenômenos da cultura política do consumo, relacionados às classes mais abastadas, como o da "camarotização da vida pública", termo criado pelo filósofo Michael Sandel para caracterizar um modo de vida das elites americanas - e também brasileiras - no sentido de segregar, evitar a "mistura de classes". Com isso, diz Sandel, “o bem público e o espírito democrático ficam em risco. Seria uma tragédia se nossos espaços públicos fossem shoppings centers, algo que acontece em vários países, não só no Brasil. Nossa identidade ali é de consumidor, não de cidadão" (Entrevista do filósofo Michael Sandel a LORES, Raul. Camarotes de VIPs são uma ameaça ao espírito democrático. Fotha de S.Paulo. 28.4.2014. Disponível em: <http://wwwl.folha.uol.com.br/ poder/ 2014/04/1446436-camarotes-de-vips-sao-uma-ameaca-ao-espirito-democratico. shtml>. Acesso em: 31 jan. 2015).

\section{Referências}

AGAMBEN, G. O que é o contemporâneo? e outros ensaios. Chapecó: Editora Argos, 2009.

ALMOND, G.; VERBA, S. The civic culture revisited: An analytic study. Boston: Little Brown, 1980. 
BARLEY, S. R. Building an institutional field to corral a government: a case to Set an Agenda for Organization Studies. Organization Studies, v.31, n.6, p.777-805, 2010.

BERNAYS, E. Propaganda. New York: H. Liveright, 1928.

BÖHM, S.; BATTA, A. Just doing it: enjoying commodity fetishism with Lacan. Organization, v.17, n.3, p.345-61, 2010.

BRADSHAW, A.; CAMPBELL, N.; DUNNE, S. The politics of consumption. Eephemera, v.13, n.2, p.203-16, 2013.

BURGESS, A. Flattering consumption creating a Europe of the consumer. Journal of Consumer Culture, v.1, n.1, p.93-117, 2001.

CALDEIRA, T. P. do R. Qual a novidade dos rolezinhos? espaço público, desigualdade e mudança em São Paulo. Novos Estudos-Cebrap, n.98, p.13-20, 2014.

CAMPRI, M. Protestos geram mais de 550 mil publicações em redes sociais. Revista Exame, 18.6.2013. Disponível em: <http://exame.abril.com.br/tecnologia/noticias/ protestos-geram-mais-de-550-mil-publicacoes-em-redes-sociais $>$. Acesso em: 10 fev. 2014.

CANCLINI, N. G. Consumidores e cidadãos: conflitos multiculturais da globalização. Editora UFRJ, 2001.

CARDUCCI, V. Culture Jamming: a sociological perspective. Journal of Consumer Culture, London, v.6, p.116-38, 2006.

Book Review: Jo Littler, radical consumption. Maidenhead: Open University Press. Journal of Consumer Culture, v.9, n.3, p.422-4, 2008.

CARUANA, R.; CRANE, A. Constructing consumer responsibility: Exploring the role of corporate communications. Organization Studies, v.29, n.12, p.1495-519, 2008.

DUFOUR, D.-R. O Divino mercado: a revolução cultural liberal. Rio de Janeiro: Companhia de Freud. 285p, 2008.

A cidade perversa: Liberalismo e pornografia. Rio de Janeiro: Civilização Brasileira, 2013.

FIGUEIREDO, R. (Org.) Junho de 2013: a sociedade enfrenta o Estado. São Paulo: Summus Editorial, 2014.

FONTENELLE, I. O nome da marca: McDonald's, fetichismo e cultura descartável. São Paulo: Boitempo, 2002.

Global responsibility through consumption?: Resistance and assimilation in the anti-brand movement. Critical Perspectives on International Business, v.6, p.256-72, 2010 .

From politicization to redemption through consumption: the environmental crisis and the production of guilt in the responsible consumer, as constructed by the business media. Ephemera (Online), v.13, p.339-66, 2013.

FRANK, T. The conquest of cool: business culture, counterculture and the rise of hip consumerism. Chicago: The University of Chicago Press, 1997.

FREDERICO, C. Da periferia ao centro: cultura e política em tempos pós-modernos. Estudos Avançados, São Paulo, v.27, n.79, p.239-55, 2013. 
GOFFMAN, K.; JOY, D. Contracultura através dos tempos: do mito de Prometeu à cultura digital. Rio de Janeiro: Ediouro, 2007.

GOHN, M. da G. Manifestações de junho de 2013 no Brasil e praças dos indignados no mundo. Petrópolis: Vozes, 2014.

GORZ, A. O imaterial: conhecimento, valor e capital. São Paulo: Annablume, 2005.

HARVEY, D. The enigma of capital: and the crises of capitalism. London: Profile, 2010. . Os rebeldes na rua: o Partido de Wall Street encontra um adversário. Blog da

Boitempo. Publicado em 2.4.2012. Disponível em: <http://blogdaboitempo.com.br/ category/colaboracoes-especiais/david-harvey/>. Acesso em: 7 mar. 2014.

HEATH, J.; POTTER, A. The rebel sell: how the counterculture became consumer culture. Sussex: Capstone Publishing Limited, 2005.

HOLT, D. Why do brands cause trouble? A dialectical theory of consumer culture and branding. Journal of Consumer Research, v.29, p.3-37, Jun. 2002.

JAMESON, F. Postmodernism, or, the cultural logic of late capitalism. Durham: Duke University Press, 1991.

JAPPE, A. Crédito à morte: a decomposição do capitalismo e suas críticas. São Paulo: Hedra, 2013.

JUBAS, K. Conceptual confusion in democratic societies: understandings and limitations of consumer-citizenship. Journal of Consumer Culture, v.7, n.2, p.231-54, 2007.

KINGSNORTH, P. Whatever happened to the revolution? Critical Perspectives on International Business, v.1, n.4, p.273-76, 2005.

KLEIN, N. Sem Logo. A tirania das marcas em um planeta vendido. Rio de Janeiro: Record, 2002.

. No Logo. Taking aim at the brand bullies. New York: Picador, 2009.

KOZINETS, R.; HANDELMAN, J. Adversaries of consumption: consumer movements, activism, and ideology. Journal of Consumer Research, v.31, p.691-704, 2004.

LIMA, V. Mídia, rebeldia urbana e crise de representação. In: MARICATO, E. et al. Cidades rebeldes: Passe Livre a as manifestações que tomaram as ruas do Brasil. São Paulo: Boitempo; Carta Maior, 2013.

LIPOVETSKY, G. A felicidade paradoxal: ensaio sobre a sociedade de hiperconsumo. São Paulo: Cia. das Letras, 2007.

MAGALA, S. Critical theory: 15 years later. Critical Perspectives on International Business, v.2, n.3, p.183-94, 2006.

MANSO, B. P. Febre funk troca o pancadão pelo luxo e ganha SP. O Estado de S. Paulo. 23.3.2013. Disponível em: <http://sao-paulo.estadao.com.br/noticias/geral,febre-funk-troca-o-pancadao-pelo-luxo-e-ganha-sp,1012482>. Acesso em:15 jan. 2015.

MARCHAND, R. Creating the corporate soul: the rise of public relations and corporate imagery in American big business. Berkeley: University of California Press, 1998.

MARICATO, E. et al. Cidades rebeldes: Passe Livre a as manifestações que tomaram as ruas do Brasil. São Paulo: Boitempo; Carta Maior, 2013. 
MOISÉS, J. A. Democratização e cultura política de massas no Brasil. Lua Nova: Revista de Cultura e Política, v.26, p.3, 1992.

MOREIRA, D. Consumo na periferia de São Paulo cresce mais que no centro. Exame. com. 4.4.2011. Disponível em: <http://exame.abril.com.br/pme/noticias/consumo-naperiferia->. Acesso em: 15 jan. 2015.

MURPHY, J. Beyond criticism: towards alternatives. Critical Perspectives on International Business, v.5, n.4, p.304-17, 2009.

NERY, N.; COUTINHO, F. Protestos fizeram governo mudar discurso sobre Copa. Folha de S.Paulo, Caderno Poder, 9 de fevereiro de 2014.

OLIVEIRA, F.; RIZEK, C. (Org.) A eva da indeterminação. São Paulo: Boitempo, 2007.

ORTEGA, R. "Funk paulista" vira moda no Youtube com carros, motos e notas de 100. Gl-Globo.com. 15.8.2012. Disponível em: <http://gl.globo.com/musica/ noticia/2012/08/funk-paulista-vira-moda-no-youtube-com-carros-motos-e-notas-de100.html>. Acesso em: 15 jan. 2015.

PAOLI, M. C. O mundo do indistinto: sobre gestão, violência e política. In: OLIVEIRA, F.; RIZEK, C. (Org.) A era da indeterminação. São Paulo: Boitempo, 2007. p.221-56.

RANCIÈRE, J. O ódio à democracia. São Paulo: Boitempo, 2014.

REICH, R. Supercapitalism: The Battle for Democracy in the Age of Big Business. Cambrige: Icon Books, 2008.

SAKAMOTO, L. Em São Paulo, o Facebook e o Twitter foram às ruas. In: MARICATO, E. et al. Cidades rebeldes: Passe Livre a as manifestações que tomaram as ruas do Brasil. São Paulo: Boitempo; Carta Maior, 2013. p.95-100.

SALECL, R. The crisis of identity and the struggle for new hegemony in the Former Yugoslavia. In: LACLAU, E. (Ed.) The making of political identities. London: Verso, 1994.

SCHOLZ, C. Campanhas gêmeas para mudar o mundo. Disponível em: <http://blogs.estadao.com.br/radar-da-propaganda/campanhas-gemeas-a-favor-de-um-mundo-melhor/>. Acesso em: 29 jul. 2013.

SECCO, L. As jornadas de junho. In: MARICATO, E. et al. Cidades rebeldes: Passe Livre a as manifestações que tomaram as ruas do Brasil. São Paulo: Boitempo; Carta Maior, 2013. p.95-100.

SOUZA, J. Os batalhadores brasileiros: nova classe média ou nova classe trabalhadora? Belo Horizonte: Editora UFMG, 2010.

STREECK, W. The crises of democratic capitalism. New Left Review, n.71, p.5-29, 2011. Citizens as customers: considerations on the new politics of consumption. New Left Review, v.76, p.27-47, July/August. 2012.

O cidadão como consumidor: Considerações sobre a invasão da política pelo mercado. Revista Piani, edição 79, 2013.

TRENTMANN, F. Citizenship and consumption. Journal of Consumer Culture, v.7, n.2, p.147-58, 2007. 
VERBA, S.; ALMOND. G. The civic culture. Political Attitudes and Democracy. Princeton (N. J.): Princeton University Press, 1963.

WALSH, K. Citizens, charters and contracts. In: KEAT, R.; WHITELEY, N.; ABERCROMBIE, N. (Ed.) The authority of the consumer. London: Routledge, 1994. p.189206.

WISNIK, J. M. Veneno remédio: o futebol e o Brasil. São Paulo: Cia. das Letras, 2008.

ZIZEK, S. Problemas no Paraíso. In: MARICATO, E. et al. Cidades rebeldes: Passe Livre a as manifestações que tomaram as ruas do Brasil. São Paulo: Boitempo; Carta Maior, 2013. p.95-100.

RESUMO - A cultura do consumo, cujas raízes estão nas décadas finais do século XIX, vem se reestruturando sob a forma de uma cultura politica do consumo. Nesta nova fase, as corporações vêm assumindo o lugar da política, concomitantemente ao enfraquecimento da noção de público a que essa própria cultura do consumo levou. Este artigo interroga os alcances e limites da crítica nesse contexto, com foco nos protestos que eclodiram no Brasil, em especial em junho de 2013. Sugere-se que esses protestos podem ser analisados a partir da perspectiva da cultura política do consumo em seu duplo movimento: na forma mesma em que se manifestaram; e na maneira como foram e ainda vêm sendo ressignificados pelos diferentes meios midiáticos, publicitários e acadêmicos. Discute-se, ao final, a ideia da democratização pelo consumo, no centro da qual pode se descortinar uma crise da própria democracia.

PALAVRAS-CHAVE: Cultura do consumo, Política do consumo, Movimentos de resistência, Empresa-cidadã, Consumidor-cidadão.

ABSTRACT - Consumer culture, whose roots lay in the final decades of the nineteenth century, has been restructuring itself as a political culture of consumption. In this new phase, corporations are taking the place of politics, while the idea of publicness is concomitantly weakened by consumer culture itself. In this context, this article questions the scope and limits of criticism, focusing on protests that erupted in Brazil, especially in June 2013. It is suggested that these protests can be analyzed from the perspective of a double movement of the political culture of consumption, i.e., both in the way in which they were expressed and how they were, and still are, interpreted by the various media, advertisers and academics. At the end, the idea of democratization by consumption is discussed, at the center of which can be found a crisis of democracy itself

KErWORDS: Consumer culture, Politics of consumption, Resistance movements, Corporate citizenship, Consumer citizenship.

Isleide Arruda Fontenelle é professora titular da Fundação Getulio Vargas (SP).

@ - idefontenelle@uol.com.br

Recebido em 21.3.2014 e aprovado em 24.2.2015.

${ }^{\text {I }}$ Fundação Getúlio Vargas, São Paulo/São Paulo, Brasil. 